\title{
KIAT-KIAT PEMBERDAYAAN PERPUSTAKAAN SEKOLAH
}

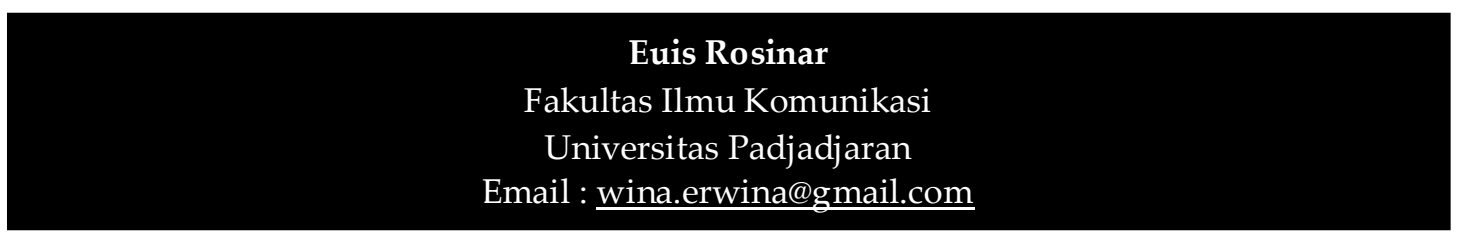

\begin{abstract}
A combination of experts' idea-generating, dignitaries in librarianship, and decision makers' concerns at the level of Government should have been made capable of realizing libraries as the facilitator of teaching-learnig process with promising outcomes. Bright learners by way of efforts made in terms of an ever enhanced curriculum should have been developing to sophisticated personalities and geared towards humans with qualities. What has gone in practice proves to be swerving to some extent in that some sort of comprehensive model of running library services is due needed: a standing structure built in the middle of the scholl; collections including books, non-books, digital; and truly Librarian (i.e. main manager of the intellectual asset). Any most interesting activities possible need to be created to make library an area of "play" being the goal of a means to accelerating a reading habit especially among children in their early age. The librarian's new paradigm should manage to penetrate the academic area of teachers in order that their collaboration with the teaching staff gives the chance to the library's functioning in an optimal way. Keywords: School library, school library design, school library activities
\end{abstract}

\begin{abstract}
ABSTRAK
Perpaduan rancang-gagas pakar, dignitary kepustakawanan, dan decision makers pada tataran Pemerintah seharusnya telah mewujudkan perpustakaan sebagai fasilitas proses belajar-mengajar yang mumpuni. Pembelajar yang dicerdaskan oleh upaya pencanggihan kurikulum sekolah seyogianya bertumbuh menjadi pribadi yang unggul dan berkembang ke arah insan yang berkualitas. Kenyataan di lapangan saat ini memerlukan suatu model menyeluruh penyelenggaraan perpustakaan: gedung yang berdiri tegap ditengah-tengah sekolah; koleksi buku, non-buku, digital; dan Pustakawan (baca: pengelola utama aset intelektual) seutuhnya. Kegiatan-kegiatan menarik harus dikreasikan untuk menjadikan perpustakaan sebagai area "bermain" yang dimaksudkan sebagai ajang penumbuhan minat baca terutama pembelajar usia dini. Paradigma baru Pustakawan selayaknya merambah ke wilayah akademik pengajar agar kolaborasinya kelak berimbas pada berfungsinya perpustakaan secara optimal.
\end{abstract}

Kata kunci: Perpustakaan sekolah, tata ruang perpustakaan sekolah, kegiatan perpustakaan sekolah

\section{A. PENDAHULUAN}


EduLib, Vol 1, No.1 Mei 2013

Salah satu tujuan pengelola yang tidak berlatar belakang diselenggarakannya layanan ilmu perpustakaan menjadi faktor perpustakaan sekolah adalah untuk penyebab utama selama ini meningkatkan kegemaran membaca. perpustakaan sekolah tidak berfungsi Perpustakaan sekolah yang merupakan sebagaimana mestinya. Kondisi ini tempat awal peserta didik menikmati terjadi di sebagian besar sekolah segala fasilitas dalam mewujudkan tujuan tersebut belum secara merata bersumbangsih dengan maksimal dan memuaskan. Keadaan ruang yang disebut sebagai perpustakaan berada di tempat "terpencil", pengap, berdebu dan tidak memenuhi standar gedung perpustakaan. Bahan perpustakaan yang ada di rak dan yang masih dibungkus plastik ditutupi debu tebal pertanda koleksi tersebut belum atau bahkan tidak terjamah tangan pengelola. Jam buka layanan yang tidak sesuai jadwal belajar peserta didik menjadikan perpustakaan tempat yang tidak masuk dalam daftar prioritas kunjungan.

Kondisi perpustakaan sekolah yang memprihatinkan, jumlah koleksi yang jauh dari memadai, layanan yang tidak diberikan secara maksimal, serta 
1. Manifesto Unesco Dan Ifla

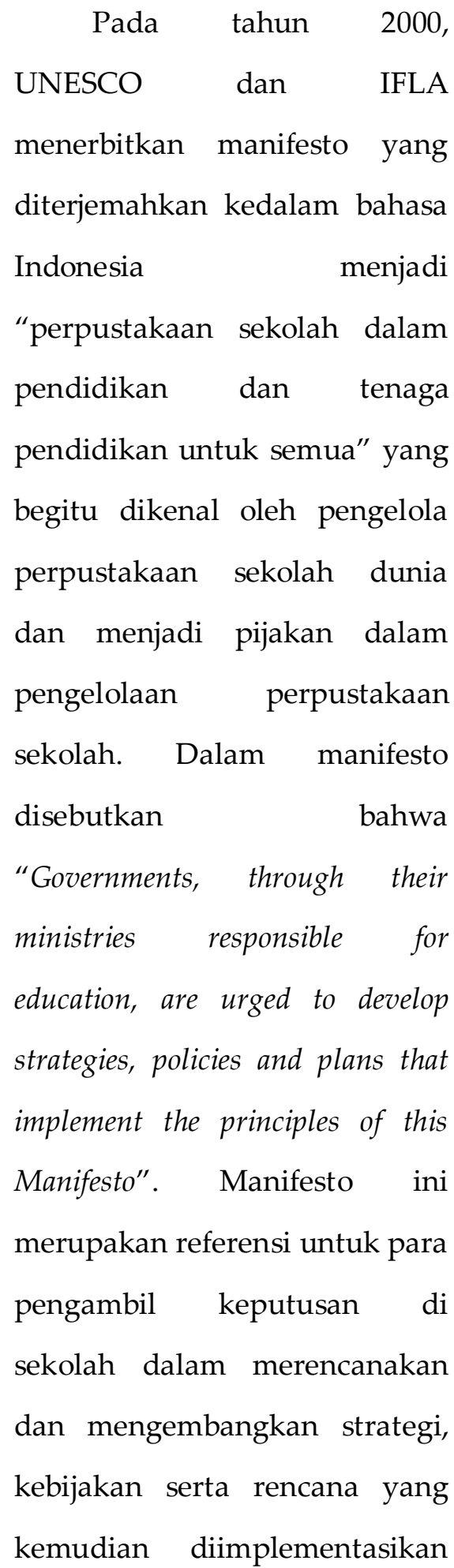

kedalam

pengelolaan

perpustakaan sekolah.

Departemen Pendidikan

Nasional pada tahun 2003

mengeluarkan Undang-Undang

Nomor 20 tentang Sistem

Pendidikan Nasional

(Sisdiknas). Dalam UU

Sisdiknas pasal 1 disebutkan

bahwa "pendidikan adalah usaha sadar dan terencana untuk mewujudkan suasana belajar dan proses pembelajaran agar peserta didik secara aktif mampu mengembangkan potensi dirinya untuk memiliki kekuatan spiritual keagamaan, pengendalian diri, kepribadian, kecerdasan, akhlak mulia, serta ketrampilan yang diperlukan dirinya, masyarakat, bangsa dan negara". UU Sisdiknas yang telah berusia 10 tahun ternyata sejalan dengan Manifesto yang diterbitkan oleh UNESCO/IFLA. Sarana untuk dapat mewujudkan hal tersebut 
EduLib, Vol 1, No.1 Mei 2013

tentu saja, salah satunya, adalah

perpustakaan.

Manifesto dan UU

Sisdiknas telah memposisikan perpustakaan dalam strata yang tinggi dalam mewujudkan proses belajar mengajar tetapi apa yang telah digariskan belum berbuah manis di negeri tercinta ini.

a. UU No. 43 Tahun 2007

UU No. 43 Tahun 2007 merupakan produk hukum tertinggi dan aspek legal yang mengatur seluruh sendi kehidupan kepustakawanan di Indonesia, termasuk perpustakaan sekolah. Secara khusus, UU No. 43 Tahun 2007 mencantumkan perpustakaan sekolah dalam pasal 23 yang dituangkan dalam 6 (enam) ayat. Dalam pasal 23 memang tidak secara tersurat mencantumkan tentang

bagaimana

pengelolaan perpustakaan

sekolah

seharusnya

dilakukan tetapi didalam

UU itu disebutkan

keberadaan perpustakaan sekolah yang harus dipelihara di tiap-tiap sekolah. Lebih lanjut disebutkan bahwa segala bentuk pengelolaan yang bersifat aturan seperti berapa jumlah koleksi yang harus dimiliki ataupun besar gedung perpustakaan yang harus berdiri dirujukkan pada standarisasi yang telah ditetapkan sebelumnya yaitu Standar Nasional Perpustakaan seperti yang tertuang dalam pasal 23 ayat 1 UU No. 43 yang menegaskan bahwa "setiap sekolah /madrasah menyelenggarakan perpustakaan yang 
memenuhi standar nasional

perpustakaan dengan

memperhatikan Standar

Nasional Perpustakaan".

Standar

Nasional

Perpustakaan (SNP) 007:

2011 dengan gamblang

merinci aspek-aspek yang

tercakup dalam

penyelenggaraan

perpustakaan tetapi

keberadaan perpustakaan

sekolah masih jauh dari

impian yang selama ini

didambakan. Banyak yang

berdalih bahwa UU No.43

tidak secara eksplisit

mencantumkan bagaimana

perpustakaan sekolah

seharusnya dikelola dengan

baik sehingga hal tersebut

menjadi suatu pembenaran

untuk tidak memasukkan

perpustakaan sebagai

daftar prioritas yang harus

dikedepankan.
Hal ini terkendala dengan

masih alotnya pembahasan

Rancangan Peraturan

Pemerintah (RPP) yang

mengatur tantang UU

No.43 menjadi Peraturan

Pemerintah (PP) yang

merupakan petunjuk teknis

dari pemerintah tentang

penyelenggaraan

perpustakaan sekolah

walaupun sudah enam

tahun berlalu sejak UU No.

43 ditetapkan.

Pengalokasian dana 5\% dari seluruh anggaran sekolah untuk perpustakaan mungkin bisa menjadi belenggu yang sangat terasa memberatkan sekolah diantara dilema penyediaan ruang kelas yang nyaman dan aman bagi siswa dan guru untuk melakukan proses kegiatan belajar mengajar. 
EduLib, Vol 1, No.1 Mei 2013

Akibatnya, banyak

sekolah mulai tingkat SD

sampai SMA baik umum,

madrasah

maupun

kejuruan tidak mampu

menyediakan perpustakaan

yang terstandar.

Dana anggaran yang

besar yang telah disiapkan

oleh

Kementrian

Pendidikan

dan

Kebudayaan belum juga

mampu menyumbang

pembangunan

perpustakaan yang layak

bagi para siswa. Menteri

Pendidikan memang telah

menyediakan anggaran

sebesar hampir 10 trilliun

pada tahun 2011 untuk

membangun perpustakaan

walaupun pada prakteknya

dana tersebut tidak

sepenuhnya diperuntukkan

bagi pembangunan

perpustakaan melainkan

harus dibagi untuk keperluan lain, seperti

memperbaiki ruang kelas yang rusak dan

peningkatan mutu, seperti pembelian buku referensi dan pengayaan serta alatalat peraga dan laboratorium (Kompas.com: 2011).

Perbaikan ruang kelas yang tidak layak untuk belajar dan peningkatan mutu pendidikan lebih menjadi prioritas utama dibandingkan

pembangunan

perpustakaan. Tidak

mengherankan apabila

sekolah-sekolah tidak memiliki gedung perpustakaan dengan sarana prasarana yang memadai. Data dari Kementerian Pendidikan Nasional hingga tahun 2011 menunjukkan bahwa dari 143.437 SD, sebanyak 79.445 
atau 55,39 persen sekolah

mewujud tanpa perpustakaan. Di SMP, 39,37 persen sekolah (13.588 dari 34.511 sekolah) tanpa perpustakaan

(Kompas.com: 2011).

Kenyataan ini sungguh ironis ditengah gencarnya pemerintah menggalakkan pendidikan dasar sembilan tahun disertai dengan minat baca yang tinggi. Bagaimana siswa dapat meningkatkan kegiatan membaca kalau jantungnya pendidikan berupa gedung perpustakaan dan segala sarana yang nyaman saja tidak tersedia di sekolah.

b. Permendiknas No 25 Tahun 2008

\section{Permendiknas}

No. 25 tahun 2008 tentang Standar Tenaga

Perpustakaan

Sekolah/Madrasah kemudian lahir untuk menegaskan pentingnya peran perpustakaan dan Pustakawan berada di lingkungan

sekolah/madrasah. Tetapi keberadaan Permendiknas tidak serta merta merubah wajah perpustakaan sekolah. Berita di koran sungguh membuat miris para pustakawan dimanapun berada. Manifesto UNESCO/IFLA, UU Perpustakaan, dan Permendiknas 25 menjadi sangat tidak berarti dengan pemberitaan di media massa yang menampar wajah perpustakaan dan para pustakawan. Citra perpustakaan sekolah yang mulai dibangun dengan susah payah kembali terpuruk. Setelah kejadian mempermalukan perpustakaan terjadi di 
EduLib, Vol 1, No.1 Mei 2013

tahun 2009, kembali tahun

2012 dunia perpustakaan sekolah tercoreng. Dua kejadian dalam kurun waktu yang berbeda tersebut menambah carut marut wajah pendidikan yang berimbas pada perpustakaan. Tahun 2013, Kepala Dinas P dan K Kabupaten Purworejo memutuskan untuk memindahkan guru bermasalah ke perpustakaan, “....sementara yang bersangkutan kami bebastugaskan mengajar dulu dan sementara menjadi petugas perpustakaan,". Lebih lanjut Kepala Dinas menjelaskan, "Dia memukul saat bertemu siswa. Sementara ini kita alihkan tugasnya ke perpustakaan agar bisa introspeksi diri," (Suara Merdeka.com: 2012).
Kejadian

pemindahtugasan kedua guru

bermasalah menunjukkan bahwa Kepala Sekolah dan pejabat terkait lainnya tidak serius menangani masalah perpustakaan dan tidak mengindahkan perintah yang telah tertuang dalam UU 43/2007 dan Permendiknas 25/2008. Perpustakaan masih dijadikan obyek penderita yaitu sebagai tempat hukuman dan pembuangan bagi orang-orang bermasalah. Hal ini tidak sejalan dengan UU 43 Pasal 30 yang menerangkan bahwa "Perpustakaan Nasional, perpustakaan umum pemerintah, perpustakaan umum provinsi, perpustakaan umum kabupaten/kota, dan perpustakaan perguruan 


tinggi dipimpin oleh
pustakawan atau oleh
tenaga ahli dalam bidang
perpustakaan". Lebih lanjut
dalam Peraturan Menteri
Pendidikan Nasional

melalui Permendiknas No. 25 tahun 2008, pasal 1 disebutkan tentang standar tenaga perpustakaan sekolah yang terdiri dari Kepala Perpustakaan dan tenaga perpustakaan yang didalamnya termaktub “sertifikat kompetensi pengelolaan perpustakaan dari lembaga yang ditetapkan pemerintah". Artinya, tidak semua/sembarang orang bisa bekerja di perpustakaan. Hanya orang-orang tertentu dengan kualifikasi tertentu yang dapat mengelola perpustakaan sekolah.

c. Perpustakaan Sekolah Ideal
Perpustakaan sekolah adalah perpustakaan yang diselengarakan sekolah dan merupakan bagian integral sekolah itu, sebagai sumber belajar, dan mendukung tercapainya tujuan pendidikan sekolah tersebut (Kamus Kepustakawan Indonesia: 2009). Perpustakaan sekolah merupakan perpustakaan yang diperuntukkan bagi siswa siswi yang mengikuti proses belajar baik di tingkat sekolah dasar, tingkat pertama, maupun tingkat atas. Siswa SD yang mempunyai karakteristik unik harus ditunjang oleh perpustakaan dengan fasilitas yang sesuai dengan kebutuhan peserta didik sesuai usia. Perpustakaan sekolah tidak hanya sekadar ruangan yang 
EduLib, Vol 1, No.1 Mei 2013

berisi buku-buku paket melainkan perpustakaan sekolah yang didominasi pemustaka kanak-kanak harus juga berisi perangkat komputer dimana siswa mendapat akses informasi yang bukan berasal dari buku saja, melainkan akses yang seluas-luasnya ke sumber-sumber informasi dalam format lain termasuk koleksi digital, dan tentu saja dukungan pustakawan yang berkompeten yang bekerja untuk membantu para siswa memenuhi kebutuhan informasinya. Johnson

menyebutkan bahwa: "the purpose of our library's physical space needs to encompass more activities than simply retrieving materials in physical formatsbooks, magazines, and audiovisual resources."
Selanjutnya Crawford dan Gorman dalam Walter (2001) memformulasikan 5 (lima) prinsip baru perpustakaan yang didasarkan pada hukum klasik Ranganathan, yaitu:

1) Libraries serve humanity;

2) Respect all forms by which knowledge is communicated;

3) Use technology intelligently to enhance service;

4) Protect free access to knowledge;

5) Hence the past and create the future.

Menurut SNI 7329:2009, dalam ruang lingkup pendidikan dasar, pertama, dan menengah harus terdapat bangunan/gedung perpustakaan yang cukup untuk menampung koleksi, 
ruang baca bagi pemustaka, maupun ruang bagi staf perpustakaan untuk bekerja. Untuk dapat berfungsi dengan baik dan memberikan kenyamanan bagi pemustaka, luas perpustakaan menurut SNI 7329:2009 untuk SD/MI seluas $56 \mathrm{~m}^{2}$, untuk SMP/MTS $126 \mathrm{~m}^{2}$; untuk SMA, MA, SMK dan MAK $168 \mathrm{~m}^{2}$, dengan pembagian ruang sebagai berikut:

1) Area koleksi seluas $45 \%$ dari ruang yang tersedia;

2) Area baca seluas $25 \%$ dari ruang yang tersedia;

3) Area staf seluas $15 \%$ dari ruang yang tersedia;

4) Area lain-lain seluas $15 \%$ terdiri dari ruang yang tersedia.
Pengadaan

bangunan/gedung

perpustakaan sekolah merupakan hal penting yang harus dilakukan dengan cermat mengingat gedung perpustakaan sekolah yang ada di manapun saat ini dibangun diatas lahan yang tidak luas. Perpustakaan sekolah harus didesain dengan menyesuaikan keadaan anak-anak yang masih sering tidak terkontrol tindakannya agar diperoleh suasana nyaman sesuai yang diinginkan agar proses belajar mengajar dapat berlangsung secara optimal. Menurut Margaret Sullivan (2011), ada 4 (empat) hal penting yang perlu dipertimbangkan sebelum memutuskan membangun gedung perpustakaan, yaitu: 
EduLib, Vol 1, No.1 Mei 2013

a. Make sure your space is flexible;

b. Remember, you're not running a book warehouse;

c. Insist on a strong infrastructure;

d. Don't sacrifice livability for beauty.

Pekerjaan tidak berhenti sampai berdirinya gedung perpustakaan. Masih ada kegiatan yang tidak bisa diabaikan begitu saja yaitu desain tata letak ruang yang harus disesuaikan dengan kebutuhan. Perpustakaan sekolah bersifat unik karena pemustakanya adalah anak-anak sehingga untuk mendesainnya perlu memasukkan unsur-unsur seperti kenyamanan, ruang yang tersedia, aliran listrik, dan yang tidak boleh diabaikan yaitu keamanan.
Sanders (2013) memberikan beberapa hal penting yang perlu diperhatikan dalam mendesain perpustakaan, yaitu:

1) Place the circulation desk in an area that allows the librarian to see every corner of the library;

2) Choose bookshelves that are the correct height;

3) Set aside an area for computers;

4) Create an area for studying and working;

5) Create a read-aloud area;

6) Set aside a place to install at least one;

7) Design at least two rooms attached to the library.

Interior yang baik tidak akan menimbulkan kesan apapun tanpa diikuti oleh pewarnaan gedung. 
Warna dipercaya dapat

menimbulkan efek spikologis dan emosional bagi manusia. Desainer harus mempertimbangkan dengan cermat efek yang akan ditimbulkan dari pemilihan warna terhadap ruangan dan terhadap anak-anak itu sendiri. Warna dapat menimbulkan kesan sempit ataupun luas untuk ruangan dan warna juga dapat menimbulkan keceriaan kepada anakanak yang memang sangat menyukai warna-warna cerah dan ceria. Pemilihan warna yang tepat dapat menimbulkan kegairahan kepada anak-anak sehingga mereka tidak lekas bosan dan mereka bisa menghabiskan waktu di perpustakaan dengan perasaan gembira dalam waktu relatif lama.

\begin{abstract}
Pemilihan warnawarna yang serasi akan menimbulkan suasana menyenangkan seperti pendapat yang dikemukakan oleh Rose (2003): "untuk mendapatkan ruangan yang cantik dan menenangkan perlu dipilihkan warna komplementer, yaitu warna-warna yang berpadu secara harmonis dan memiliki intensitas yang senada". Hal serupa juga dikemukakan oleh Prawira (1989) “penampilan sebuah ruangan dapat berubah secara radikal bila warna dindingnya diubah dengan warna kontrasnya".

Para ahli meyakini bahwa apabila suatu lingkungan sekolah dirancang dengan baik akan memberi efek positif
\end{abstract}


EduLib, Vol 1, No.1 Mei 2013

bagi kegiatan proses belajar mengajar dan mengurangi perilaku negatif siswa. Pemilihan warna harus disesuaikan dengan pencahayaan, khususnya pencahayaan buatan, yang ada dalam suatu ruangan agar warna asli yang diinginkan tidak berubah karena penyinaran yang tidak sesuai akan merubah warna aslinya. Dua hal penting yang perlu dipertimbangkan yang berhubungan dengan penggunaan warna, yaitu rasio kekuatan cahaya pada bidang-bidang umum dan lingkungan berwarna yang harus dapat memantulkan cahaya antara 50\% dan 60\%. (Prawira: 1989).

2. Program Perpustakaan Sekolah Perpustakaan sekolah selama ini dikenal sebagai sumber belajar yang sepi, membosankan, dan bukan tempat favorit untuk dikunjungi oleh para siswa. Kondisi perpustakaan yang seperti itu harus segera diubah menjadi perpustakaan yang selalu menjadi tujuan kunjungan siswa saat mereka tidak berada didalam kelas. Masalahnya adalah bagaimana perpustakaan sekolah mengubah sosoknya menjadi tempat yang penuh inspirasi dan menyenangkan untuk dikunjungi oleh para siswa di saat mereka berada diluar ruang kelas.

Mengundang anak-anak dan meminta mereka untuk datang ke perpustakaan bukan hal yang mudah karena citra perpustakaan yang membosankan dan sepi yang melekat selama ini. Kerjasama Guru dan Pustakawan belum tampak dalam membentuk siswa untuk mencintai 
perpustakaan sebagai wahana yang menyenangkan bagi mereka untuk berinteraksi dengan informasi dan pengetahuan dalam pemenuhan tugas-tugas edukatif di kelas. Anak tidak akan mencintai perpustakaan tanpa ada rangsangan dari Pustakawan, Guru, bahkan orang tua. Anak tidak akan pernah tahu isi perpustakaan apabila tidak diperkenalkan kedalamnya. Ghezzi (2013), seorang jurnalis penulis dunia pendidikan dan sekolah, memberikan 12 saran ataupun strategi agar anak mau berkunjung ke perpustakaan. Berikut adalah 12 strategi Ghezzi yang telah disesuaikan dengan perpustakaan sekolah, yaitu:

a. Get the child a library card

Tunjukkan kepada anak betapa menyenangkannya meminjam buku, games, puzzle, dan VCD dengan menggunakan

kartu

perpustakaan sendiri untuk dibawa pulang dan kemudian

mengembalikannya sesuai tanggal.

b. Visit often

Yakinkan anak bahwa perpustakaan adalah area yang menyenangkan untuk dikunjungi sehingga menjadikannya tujuan kunjungan dengan jadwal teratur.

c. Teach child how to find books and media at the library

Memberi pengetahuan kepada anak bagaimana koleksi disusun sistematis dan diletakkan pada tempatnya dan dan bagaimana menemukannya dengan mudah.

d. Visit different branches

Ada perpustakaan sekolah yang mempunyai cabang di sekolah yang sama di 
EduLib, Vol 1, No.1 Mei 2013

tempat lain dengan

keunikannya sendiri.

Sarankan kepada mereka

mengunjungi perpustakaan

cabang tersebut untuk

mendapat pengalaman

baru.

e. Get a calendar of activities

Tempelkan dan sebarkan

jadwal kegiatan yang

dirancang perpustakaan

setiap bulan di majalah

dinding sekolah ataupun di

tempat yang telah

disediakan

di

perpustakaan.

f. Consider child's interests

Bantu anak memilihkan

bacaan yang tepat dan

mulai dari yang disukai.

g. Like the movie? Love the book

Apabila anak sangat

menyukai satu film dan

melihatnya berulang-ulang,

sarankan dia untuk melihat

film lain dari tema sejenis

dari DVD atau audio book. h. Explore magazines

Anak-anak tidak suka membaca buku. Sarankan untuk membaca majalah dari tema-tema yang disukai seperti olahraga dan dunia binatang.

i. Be a role model

Pustakawan, Guru dan orang tua khususnya harus menjadi contoh bagi anakanak. Tunjukkan kepada mereka bahwa membaca adalah kegiatan yang menyenangkan.

j. Suggestions for improvement

Perpustakaan menerima saran dari para siswa untuk kemajuan perpustakaan memberikan layanan.

k. Be an advocate

Perpustakaan selalu menjadi pihak yang dikalahkan. Pustakawan harus dapat meyakinkan para pengambil kebijakan akan pentingnya 
perpustakaan sehingga

perpustakaan menjadi

wahana yang selalu

mewujud sebagai prioritas

untuk didanai.

1. Make the library a priority

Yakinkan siswa agar

memasukkan perpustakaan

sebagai prioritas yang

dikunjungi setelah mal atau

tempat menyenangkan

lainnya.

Perpustakaan sekolah di Indonesia pada umumnya, dan di daerah pada khususnya, memberikan hanya layanan standar yang diberikan secara teratur pada jam sekolah. Pelayanan hanya berkisar pada lingkaran pelayanan sirkulasi dan penyediaan ruang baca tanpa ada kegiatan-kegiatan yang dapat merangsang dan menarik para siswa untuk datang untuk kemudian mencintai perpustakaan. Ghezzi (2013) menuliskan bahwa:
“.......... In addition to wonderful

books, today's libraries offer multimedia options, community events, fun activities, and moreand all for free." Pernyataan ini didukung oleh Heyden (2013) dengan pendapatnya "One of the best ways to get kids in the school library is to hold inspiring events, organize book fair and offer exciting library activities".

Perpustakaan sekolah harus selalu terbuka 24 jam selama tujuh hari dalam seminggu. Tidak ada alasan lagi bagi siswa untuk tidak mengunjungi perpustakaan manakala mereka mendapat tugas dari guru yang mengharuskan mendatangi perpustakaan untuk memperoleh informasi yang diperlukan. Posisi Pustakawan yang berada di depan harus membuat perpustakaan menjadi tempat yang tidak lagi sunyi dan Pustakawan bukan lagi 
EduLib, Vol 1, No.1 Mei 2013

menjadi seseorang yang selalu shhhh! Saat situasi perpustakaan sedikit ramai karena dipernuhi siswa. Pustakawan sekolah harus selalu siap membantu memecahkan masalah para siswa yang mengalami kesulitan yang dimulai dari akses informasi untuk memenuhi kebutuhan informasi para siswa sampai hal yang mungkin dianggap sepele seperti menyediakan tempat aman bagi siswa yang mendapat perlakukan tidak bagus dari teman lainnya selama di perpustakaan. Seperti yang dilakukan Young (2013) misalnya, seorang Pustakawan sekolah dan penulis untuk The Centered School Library, saat menuliskan 12 hal yang dilakukannya dan dituangkan dalam The interest of Librarydoor: 12 Things I'm doing when you think all is "shhh"!.

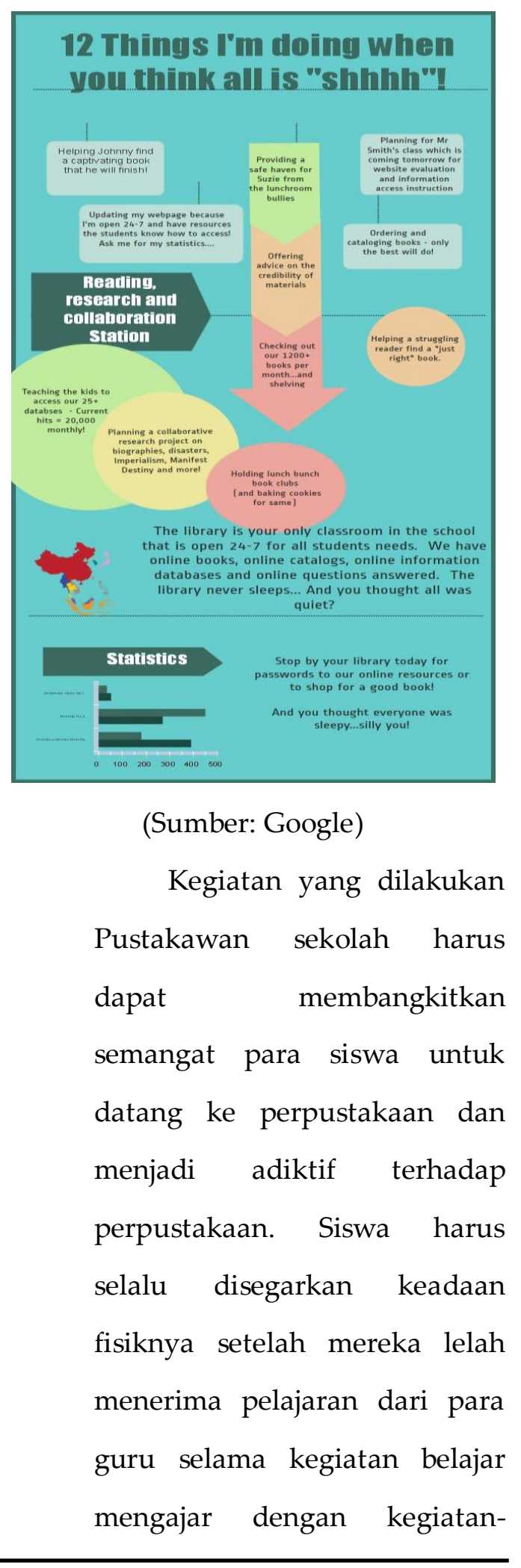


kegiatan yang diadakan oleh perpustakaan. Kegiatan yang diberikan harus dapat memberikan kegembiraan dan memberikan tantangan kepada para siswa karena pada dasarnya anak-anak menyukai tantangan, "children love a challenge..." Heyden (2013). Heyden, yang seorang pencerita, menyarankan beberapa kegiatan diantaranya:

a. Exciting Library Quizzes

Acara quiz dari program televise layak untuk diadopsi dengan memberikan pertanyaan seputar perpustakaan dan ilmu pengetahuan umum yang mengharuskan anak membaca untuk mengetahui jawaban yang benar.

b. Fun Library Activities

Kegiatan fun library diberikan kepada para siswa, yang diantaranya mencari harta karun yang petunjuknya ada pada halaman tertentu dari buku yang berbeda-beda, lomba berpakaian dengan tema yang diambil dari buku cerita yang ada di perpustakaan, dan lomba mendesain dan menggambar poster dan bookmark tentang perpustakaan. Kegiatan ini memberikan pembelajaran kepada anak-anak untuk gemar membaca dan sekaligus memberikan kegembiraan kepada mereka saat melakukannya.

c. Holding a Library Book Fair

Mengundang penerbit untuk mengadakan pameran buku di perpustakaan dengan memberikan potongan 
EduLib, Vol 1, No.1 Mei 2013

harga untuk setiap

pembelian.

d. Organizing an Author Visit

to the School

Mengundang penulis

buku terkenal dan pemula

ke perpustakaan untuk

memberikan workshop

ataupun ceramah tentang

penulisan kepada para

siswa.

e. Educational Library

Software

Software edukasi untuk

perpustakaan seperti

Renaissance Reading atau

Junior

Librarian dan quiz online

diberikan untuk mendidik

siswa gemar membaca

sekaligus melek teknologi.

Melalui kegiatan ini dapat

diketahui reading level atau

tingkat membaca mereka.

f. Educational Games for the

Library
Games merupakan

kegiatan yang paling

disukai anak-anak.

Kegiatan bermain games

bisa dipertimbangkan

untuk diberikan kepada

para siswa, seperti role

playing (bermain peran).

Para siswa diminta untuk

memainkan peran dari

tokoh-tokoh ataupun

karakter yang diambil

dari buku cerita yang ada

di perpustakaan. Selain

kegiatan bermain peran,

kegiatan lain yang dapat

melatih daya kerja otak

seperti permainan catur juga dapat diberikan

kepada para siswa.

Kegiatan menarik yang

dirancang oleh staf perpustakaan untuk merangsang siswa mengunjungi perpustakaan dan penyedian bahan bacaan di perpustakaan didasarkan pada minat siswa 
pada bacaan-bacaan yang digemarinya. Pustakawan hendaknya tidak memaksa siswa membaca buku yang bukan menjadi interest (ketertarikan)nya. Pustakawan harus bisa berkompromi terhadap bacaan-bacaan yang diminati siswa dengan tetap melakukan pengawasan dan advokasi. Modi (2009), seorang peminat dan pemerhati kesusastraan anak-anak, memberikan beberapa tindakan yang seharusnya dan tidak seharusnya dilakukan oleh pihak perpustakaan kepada para siswa sebagai pemustaka perpustakaan sekolah. Modi menyarankan perpustakaan untuk:

a. Memberikan keleluasaan kepada para siswa untuk mengekspos berbagai macam dan sebanyak mungkin bacaan; b. Memberikan dukungan kepada para siswa untuk berani menyampaikan bacaan apa saja yang menjadi dan bukan menjadi minatnya;

c. Menyarankan buku-buku bacaan yang menjadi minat para siswa untuk mendalaminya;

d. Mengijinkan siswa untuk mengeksplorasi buku-buku lain untuk kategori usia yang berbeda dari dirinya;

e. Memberikan nuansa dan ruang baca yang nyaman;

f. Membiarkan para siswa untuk merasakan buku dengan cara menyentuh, memeluk, dan bahkan mencium baunya.

Modi (2009) juga menyarankan beberapa hal yang tidak seharusnya dilakukan oleh staf perpustakaan, yaitu:

a. Memaksa anak-anak untuk membaca buku-buku tertentu, 
EduLib, Vol 1, No.1 Mei 2013

seperti ensiklopedia, kamus,

dan buku-buku yang

berhubungan dengan silabus

mata pelajaran;

b. Membentuk kesan bahwa membaca adalah pekerjaan siasia dan membuang waktu;

c. Membunuh kesenangan siswa membaca dengan memaksa mereka membuat riviu untuk setiap buku yang telah dibaca;

d. Memaksakan selera membaca pribadi kepada siswa;

e. Kaku tentang age-appropriateness (batasan usia dengan kepantasan bacaan). Anak seusia dalam satu kelompok belum tentu memiliki kesamaan ketertarikan untuk tema cerita yang dibaca;

f. Menjadikan perpustakaan sebagai kepanjangan dari ruang kelas;

g. Menyimpan buku di tempat yang terkunci sehingga menyulitkan akses.
UU No. 43/2007 tentang Perpustakaan dan Permendiknas No. 25/2008 merupakan landasan berpijak bagi para pemangku kepentingan, khususnya di sekolah, untuk mulai membenahi keadaan perpustakaan sekolah yang selama ini terabaikan. Pejabat sekolah sebaiknya tidak hanya memberikan gedung perpustakaan yang layak tetapi juga menyediakan bahan perpustakaan bermutu dengan staf berkualitas untuk dapat melayani para siswa yang datang ke perpustakaan.

Gedung dan koleksi yang memadai tidak cukup untuk dapat mengundang para siswa datang ke perpustakaan. Pustakawan atau pengelola berkompeten pada perpustakaan sekolah harus dapat menciptakan kegiatan-kegiatan yang menarik, memberikan kegembiraan, dan dapat menimbulkan rangsangan kepada para siswa untuk menjadi gemar membaca dan menjadikan perpustakan sebagai area paling utama

\section{KESIMPULAN}


untuk dikunjungi selain mal ataupun area bermain.

Perpustakaan sekolah sudah saatnya tidak lagi dipandang sebagai tempat yang sunyi, statis dan membosankan. Perpustakaan sekolah harus merupakan sarana belajar dan area bermain yang menyenangkan bagi para siswa. Heyden (2013) menuliskan: "The key to successful school libraries is to balance study and reading with fun acticities that stimulate children and inspire them to explore further".

Pustakawan sekolah bukan lagi seseorang yang kaku dan selalu mengucapkan "sshhhh" manakala suasana perpustakaan ramai. Pustakawan sekolah harus menciptakan perpustakaan sebagai tempat belajar dan sumber informasi yang dengan cuma-cuma dan mudah untuk didapatkan. Pustakawan juga harus menjadi pembimbing yang telaten dan ramah bagi para siswa dalam membentuk mereka menjadi pencari informasi yang baik dengan mempergunakan seluruh fasilitas yang ada di perpustakaan. Brodie dalam Ghezzi (2013) menuliskan: “Children's librarians help children develop a zest for learning and a lifelong love of reading. They also assist in finding answers to questions, and bring children and resources together," Pemberdayaan siswa, dalam hal ini, merupakan upaya yang harus senantiasa dilakukan.

\section{DAFTAR PUSTAKA}

Fontichiaro, Kristin and Buffy

Hamilton (ed.) School Libraries:

What's Now, What's Next, What's

Yet to Come.

http://www.smashwords.com/bo

oks/download/96705/1/latest/0/0/

school-libraries-whats-now-

whats-next-whats-yet-to-

come.pdf. Akses. 26 Februari

$\underline{2013}$

Ghezzi, Patti. 12 Ways To Help Your

Child Love the Library.

http://www.schoolfamily.com/schoolfamily-articles/article/10853-12ways-to-help-your-child-lovethe-library. Akses, 11 November 2013. 
Harsana, Lasa.( 2009) Kamus

Kepustakawanan Indonesia.

Yogyakarta: Pustaka.

Harsana, Lasa. (2007.)Manajemen

Perpustakaan Sekolah. Yogyakarta:

Pinus.

Heyden, Louise. Exciting Activities for the School Library.

http://suite101.com/a/excitingactivities-for-the-school-librarya123969. Akses, 11 November 2013.

Johnson, Doug.( 2013.) The Indispensable Librarian: surviving and thriving in school libraries in the information age. Santa Barbara: Linworth,

Kholiq, Nur. Guru Pemukul Siswa

Dibebastugaskan Mengajar.

http://www.suaramerdeka.com/v

1/index.php/read/news/2012/03/1

8/112794/Guru-Pemukul-Siswa-

Dibebastugaskan-Mengajar.

Akses, 27 Januari 2013

Kompas.com. Sekolah Terbelenggu UU

Perpustakaan.

http://edukasi.kompas.com/read/ 2011/04/04/10332657/Sekolah.Ter
belenggu.UU.Perpustakaan.

Akses, 31 Januari 2013.

Kompas.com. Rp 9,9 Triliun Ternyata

Masih Kurang.

http://edukasi.kompas.com/read/

2011/04/01/1207155/Rp.9.9.Triliun

.Ternyata.Masih.Kurang. Akses,

31 Januari 2013.

Modi, Chintan Girish. Libraries can be

fun.http://www.teacherplus.org/2

008/august/libraries-can-be-fun.

Akses, 11 November 2013

Pedoman Perpustakaan Sekolah

IFLA/UNESCO. Terjemahan dari

School Library Guideliness

IFLA/UNESCO. www.pnri.go.id.

Akses, 1 Februari 2013.

Peraturan Menteri Pendidikan Nasional

Republik Indonesia Nomor 25 Tahun

2008

Tentang Standar Tenaga Perpustakaan

Sekolah/Madrasah. http://bsnp-

indonesia.org/id/wp-

content/uploads/tenaga/Permen

25 Th-2008.pdf. Akses, 4 Februari

2013. 
ISSN : 2089-6549

Prastowo, Andi.( 2012) Manajemen

Perpustakaan Sekolah Profesional.

Yogyakarta: Diva

Press.

Prawira, Sulasmi Darma. (1989) Warna

Sebagai Salah Satu Unsur Seni E

Desain. Jakarta: Depdikbud.

Rose, Sue. (2003) 100 Ide Kreatif untuk

Warna. Jakarta: Erlangga.

Sanders, April. How to Design a School

Library.

http://www.ehow.com/how 5079

514 design-school-library.html.

Akses, 1 Februari 2013.

School Libraries: making a difference.

http://www.schoollibrariesadvocacy.or

g.uk/toolkit/making a difference.

pdf. Akses, 11 November 2013

Standar Nasional Indonesia Bidang

Perpustakaan dan Kepustakawanan.

http://www.pnri.go.id. Akses, 14

November 2013

Sullivan, Margaret. Divine Design: How

to create the 21st-century school library of your dreams.

http://www.schoollibraryjournal. com/slj/home/889642- 312/divine design how to create

.html.csp. Akses, 1 Februari 2013

Undang-Undang Republik Indonesia

Nomor 43 Tahun 2007 Tentang

Perpustakaan. Jakarta:

Perpustakaan Nasional RI, 2009.

Undang-undang Republik Indonesia

Nomor 20 Tahun 2003 Tentang

Sistem Pendidikan Nasional.

http://www.hukumonline.com.

Akses tanggal 1 Februari 2013

Walter, Virginia A. (2001)Children

Librarie: getting it right. Chicago:

American Library Association.

Young, Cari.

https://www.pinterest.com/pin/26

2897696970722398/. Akses, 11

November 2013

Yusuf, Pawit M. dan Yaya Suhendar.(

2010) Pedoman Penyelenggaraan

Perpustakaan Sekolah. Jakarta:

Kencana Prenada Media Group.

http://portal.mahkamahkonstitusi.go.id

LeLaw/mg58ufsc89hrsg/34865d71

$\underline{\text { a44fee802244244ac7366eadbe3a3bf }}$

$\underline{\text { 4fa.pdf }}$ 